\title{
Profiles of Religiousness, Spirituality, and Psychological Adjustment in Emerging Adults
}

\author{
Carolyn McNamara Barry \\ Loyola University Baltimore \\ Jennifer L. Christofferson \\ Loyola University Baltimore \\ Eric P. Boorman \\ Morgan State University \\ Larry J. Nelson \\ Brigham Young University - Provo, larry_nelson@byu.edu \\ Follow this and additional works at: https://scholarsarchive.byu.edu/facpub \\ Part of the Other Social and Behavioral Sciences Commons
}

\section{Original Publication Citation}

Barry, C. M., Christofferson, J. L., Boorman, E., \& Nelson, L. J. (2020). Profiles of religiousness, spirituality, and psychological adjustment in emerging adults. Journal of Adult Development, 27, 201-211.

\section{BYU ScholarsArchive Citation}

Barry, Carolyn McNamara; Christofferson, Jennifer L.; Boorman, Eric P.; and Nelson, Larry J., "Profiles of Religiousness, Spirituality, and Psychological Adjustment in Emerging Adults" (2019). Faculty Publications. 4709.

https://scholarsarchive.byu.edu/facpub/4709

This Peer-Reviewed Article is brought to you for free and open access by BYU ScholarsArchive. It has been accepted for inclusion in Faculty Publications by an authorized administrator of BYU ScholarsArchive. For more information, please contact ellen_amatangelo@byu.edu. 


\title{
Profiles of Religiousness, Spirituality, and Psychological Adjustment in Emerging Adults
}

\author{
Carolyn McNamara Barry ${ }^{1}$ (i) $\cdot$ Jennifer L. Christofferson ${ }^{1} \cdot$ Eric P. Boorman $^{2} \cdot$ Larry J. Nelson $^{3}$
}

Published online: 30 May 2019

(c) Springer Science+Business Media, LLC, part of Springer Nature 2019

\begin{abstract}
Although emerging adults are engaged in heightened levels of meaning-making (Barry and Abo-Zena (eds) in Emerging adults' religiousness and spirituality: meaning-making in an age of transition. Oxford University Press, New York, 2014), research has focused on either religiousness or spirituality $(\mathrm{R} / \mathrm{S})$ in each study. While R/S individually have been associated with emerging adults' psychological adjustment (Rew and Wong in J Adolesc Health 38:433-442, 2006), scholars have rarely explored the specific profiles of R/S adjustment. Thus, a diverse group of undergraduate students $\left(N=792 ; M_{\text {age }}=19.61\right.$, $\mathrm{SD}=1.86 ; 69 \%$ women) completed questionnaires online involving these constructs. Preliminary analyses revealed strong correlations between R/S, which might be indicative of multicollinearity. A two-step cluster analysis revealed three distinct adjustment profiles. Adjustment was positive in instances of high R/S and low R/S. However, moderate levels of R/S were associated with poor adjustment. Subsequent research may verify these profiles and further explore multicollinearity in religiousness and spirituality research.
\end{abstract}

Keywords Religiousness · Spirituality · Identity · Self-esteem · Depressive symptoms · Psychological adjustment · Emerging adults

Although Erikson (1968) contended that adolescents are focused on the task of identity development, he noted that this complicated task often extends into the twenties. Arnett (2015) argues that 18-29 years constitutes a distinct life stage known as emerging adulthood, which is characterized by five features: identity exploration, instability, self-focus, feeling in-between, and possibilities/optimism. With delayed entrance into adult roles of marriage and parenthood (Arnett 2015), these emerging adults, particularly those attending universities, engage in heightened exploration of their values and beliefs through curricular and co-curricular activities, including their religiousness and spirituality $(\mathrm{R} / \mathrm{S})$.

Although scholars have examined the processes that promote children's and adolescents' R/S (Boyatzis 2013), less is known about emerging adults' R/S (e.g., Barry and AboZena 2014). According to the Pew Forum on Religion and

Carolyn McNamara Barry

cbarry@loyola.edu

1 Loyola University Maryland, Baltimore, MD, USA

2 Morgan State University, Baltimore, MD, USA

3 Brigham Young University, Provo, UT, USA
Public Life (2012), emerging adults claim their religious beliefs are less important across this decade than earlier, whereas their spiritual beliefs tend to increase during this time, particularly for women (Astin et al. 2011). In contrast, religious and spiritual practices tend to decline in the early part of emerging adulthood, but later increase in some, but not all emerging adults (Smith and Snell 2009). Moreover, a growing subgroup of emerging adults identifies as spiritual, but not religious (Pew Forum on Religion and Public Life 2012).

As summarized in Pargament et al. (2013), scholars agree on the multifaceted nature of R/S but disagree as to which construct is broader, with religiousness encompassing "predefined belief and rituals along with institutionally based involvement, [whereas spirituality] more often connotes an individualized, experientially based...positive values, such as connectedness, meaning, self-actualization, and authenticity" (p. 11). Still Zinnbauer et al. (1997) contend that spirituality is the forerunner of religiousness. While spirituality used to be based upon a religion, increasingly the term also may be derived from a secular source (Koenig 2008). Scholars have often struggled developing measures that assess these constructs separately, and some use the R/S terms interchangeably (Koenig 2008). 
In sum, religiousness and spirituality are distinct constructs but they are interrelated in many important ways (e.g., conceptually, methodologically, practically). Thus, research is needed that carefully examines R/S jointly.

\section{Religiousness and Spirituality}

The third decade of life is a unique time to examine the R/S interplay. Although emerging adults' $\mathrm{R} / \mathrm{S}$ is related to their faith activities in their home during childhood (Barry et al. 2013) through processes of intergenerational transmission of religion (Silverstein and Bengston 2018; see Nelson 2014 for review), emerging adulthood is the period in which many emerging adults begin to separate their religiousness from their spirituality (Pew Forum on Religion and Public Life 2012). For example, many emerging adults report the importance of spiritual beliefs despite their practice of religious beliefs decreasing during the early part of emerging adulthood (Smith and Snell 2009). Certainly, it is not surprising that we start to see changes in young people's R/S given the tendency for emerging adults to engage in self-exploration in multiple and changing social contexts presented in this period of life (Arnett 2015) that have the potential to expose them to an increasing variety of values, beliefs, and practices. Because of greater exposure to a variety of ideologies, emerging adults are likely to take a cafeteria approach to forming and practicing their R/S, whereby individuals adopt a variety of views from different R/S systems into one worldview (Smith and Snell 2009). For instance, an emerging adult might seamlessly incorporate media notions, such as "The Force" from Star Wars, with both a traditional Christian doctrine, and practices of meditation from Zen Buddhism (Arnett and Jensen 2002). Given this cafeteria approach to forming beliefs, it is easy to see why many young people value spirituality, while not conforming their personal beliefs with any one religious tradition resulting in a growing number of emerging adults who identify themselves as non-religious (including those who identify as spiritual, but not religious; see Zuckerman et al. 2016). Taken together, current work points to the complex relation of two distinct but interrelated aspects of emerging adults' identity (religiousness and spirituality); the complexity of $\mathrm{R} / \mathrm{S}$ interaction only increases when we begin to examine the links of R/S with indices of adjustment and maladjustment.

\section{Religiousness and Spirituality in Psychological Adjustment}

As distinct constructs, religiousness and spirituality, respectively, have been associated with emerging adults' psychosocial adjustment (for reviews, see Yonker et al. 2012). Specifically, emerging adults' religious beliefs have been associated with adjustment, including high levels of self-esteem (Rew and Wong 2006) and academic performance (Good et al. 2009). Additionally, religiousness has been associated with depressive symptoms (Shannon et al. 2018) and hooking up (Burdette et al. 2009). Spirituality has been associated with some adjustment outcomes, such as effective coping mechanisms (Hill et al. 2000), increased levels of moral development and psychological well-being, yet lower levels of negative moods (Powers et al. 2007) and perceived stress (Heintzman and Mannell 2003). Taken together, existing work examines the links between R/S, respectively, and indices of adjustment and maladjustment. Again, the results paint a very complicated picture as both constructs have been linked to positive and negative outcomes. Most of these studies have examined R/S as separate and distinct constructs, yet literature shows them also to be interrelated in many ways. Indeed, little, if any, work has attempted to identify the within-person relative levels of R/S in the same study (c.f., Klemmack et al. 2007) pointing to the need to examine the relations between R/S and psychological adjustment within individuals (i.e., from a person-centered approach rather than variable-centered approaches) better.

\section{Profiles of Psychological Adjustment}

Although there is ample research on R/S and psychological adjustment using a variety of variable-centered statistical approaches (e.g., factor analysis, correlational analysis, structural equation models), few researchers have taken a person-centered approach in which specific profiles or clusters of individuals are identified who share particular attributes. One such person-centered method to identify individuals who share various profiles of R/S and adjustment is cluster analysis. Cluster analysis is a procedure whereby persons are divided into separate groups or clusters based upon their similarities; this statistical technique is particularly useful when assessing R/S and psychological adjustment as it can determine how R/S and psychological adjustment variables interact with one another while additionally determining differences among these groups according to their levels of R/S and adjustment. Additionally, cluster analysis can identify unusual profiles of R/S and psychological adjustment which may be overlooked by variable-centered statistical procedures such as multiple regression analyses, correlational analyses, and structural equation models (Kristeller et al. 2011).

Person-centered approaches have been employed effectively to understand various profiles of emerging adults' adjustment and maladjustment better, including links between various profiles of identity development and adjustment (Benson and Elder 2011; Luyckx et al. 2008). In one of the only person-centered approaches looking at 
religiousness, Jankowski et al. (2015) identified three profiles, or groups of young people from 30 universities in the US, based on varying levels of religious involvement, salience, and religious motivations. The three groups then differed on a variety of indices of adjustment (e.g., hazardous alcohol use). In sum, variable-centered approaches can establish links between variables (e.g., religiousness and adjustment) but person-centered approaches allow comparison of individuals who are similar in certain variables with those who differ on those same dimensions. As such and given that few studies examine the interrelatedness of R/S, we chose to employ a cluster analysis to identify different groups of emerging adults who vary along each of these dimensions ( $\mathrm{R} / \mathrm{S}$ and adjustment).

\section{Current Study}

Given the normative challenges faced in the third decade of life (Arnett 2015), it is essential to understand how R/S and psychological adjustment manifest in emerging adults. Emerging adults are faced with the awesome task of individuation, which in turn promotes their identity exploration (and hopefully commitment), as well as their self-worth (Arnett 2015). Amidst the instability that comes with this decade and becoming more autonomous, depressive symptoms are possible (Salmela-Aro et al. 2008). Collectively then, these three areas of adjustment (identity, self-worth, and depressive symptoms) capture salient positive and negative indicators of emerging adults' psychological adjustment.

\section{Identity}

Identity development is an evolving and complex developmental task that becomes salient starting in adolescence, continues into adulthood, and becomes one of the central facets to positive adaptation in late adulthood (for review, see Schwartz et al. 2015). Identity can develop across multiple domains (e.g., gender, romantic relationship, career) but can also occur within an overall sense of oneself as a person. Furthermore, identity development involves two important processes, namely, exploration and commitment. Given university-attending emerging adults' increased independence and less responsibility towards others (Arnett 2015), they often spend more time exploring than committing to their identity, particularly in their early twenties. According to Marcia and Strayer (1996), this tension between identity exploration and commitment has the capacity to shape young people's development.

For many emerging adults, the process of identity development may include exploring completely new areas of their lives (e.g., career) but it might also include examining the beliefs in which they were raised. Indeed, their increased autonomy may serve as a catalyst to the process of re-evaluating, adjusting, and perhaps renouncing previously held beliefs. The replacement of old values and roles with new ones requires them to adjust psychologically (Côté 2000). Hence, conceptually, it seems that varying levels of R/S may be linked to identity development. Empirically, there is emerging evidence to support this notion. For instance, college students high in quest (i.e., viewing religion as a search for truth) but low in intrinsic and extrinsic religious motivation) reported the lowest religiousness and least identity commitment compared to other groups (Cook et al. 2014). Although these results point to the notion that religiousness may be linked to identity formation, it does not consider aspects of spirituality. However, it does point to the possibility that a unique profile of R/S and identity development (i.e., identity exploration and commitment) may appear in emerging adults, which was undertaken in the current study.

\section{Self-worth}

In examining indices of adjustment, it is important to include self-worth as it has been identified as an important aspect of flourishing in emerging adulthood (Nelson and PadillaWalker 2013). Given the instability of emerging adulthood, self-worth is likely to fluctuate (Arnett 2015) based on a variety of individual factors. Specifically, there is evidence that R/S is associated with emerging adults' self-worth (Rew and Wong 2006) but, to date, little research has examined $\mathrm{R} / \mathrm{S}$ variables simultaneously in relation to self-esteem, and none have taken a person-centered approach to see how various patterns of religiousness, spirituality, and self-worth might may be exhibited within different groups of individuals; this task was undertaken in the current study.

\section{Depressive Symptoms}

One potential barrier to positive psychological adjustment is depressive symptoms, which for some emerging adults persist at high rates across the third decade due in part to genetic predisposition and the typical age of onset (SalmelaAro et al. 2008). Despite the increased autonomy given to emerging adults, there is heightened instability for young people in many areas of their lives including romantic partners, residences, and work (Arnett 2015). As a result, many emerging adults experience multiple internal and external stressors and pressures. Not surprisingly then, changes in mental health are likely, which can be related adversely to psychological adjustment (e.g., decreased quality of life; Lewinsohn et al. 1997).

$\mathrm{R} / \mathrm{S}$ have been associated with greater levels of physical and mental health (Ellison and George 1994). Specifically concerning religiousness, church attendance, religious coping, and religious activities (e.g., prayer) have been found 
to be associated with lower levels of depressive symptoms (Shannon et al. 2018). Also, spirituality has been related to college students' personal-emotional adjustment (Gilliam et al. 2008). Taken together, it appears that in work employing variable-centered methods for $\mathrm{R} / \mathrm{S}$ is associated with depressive symptoms. However, little is known about the multiple ways in which individuals reflect different patterns of R/S in relation to depressive symptoms, which was explored in this study.

\section{Overview}

Given the normative challenges faced in the third decade of life (Arnett 2015), it is essential to understand how R/S and psychological adjustment manifest in emerging adults. R/S have been shown to be related positively to psychological adjustment (Yonker et al. 2012), even though little is known about how such adjustment varies by emerging adults' religiousness relative to their spirituality. In other words, based on variable-centered methods, we know that $\mathrm{R} / \mathrm{S}$, respectively, may be linked to indices of adjustment and maladjustment, but little is known about the variation of individuals regarding R/S and adjustment. Thus, the purpose of this study was to employ a cluster analysis to identify different profiles of R/S and psychological adjustment in emerging adulthood. We hypothesized that two profiles would emerge: high R/S with positive adjustment (i.e., higher self-worth and identity, but lower depressive symptoms) and low R/S with negative adjustment (i.e., lower self-worth and identity, but higher depressive symptoms).

\section{Method}

\section{Participants}

Participants for this study were drawn from a study of emerging adults entitled Project READY (Researching Emerging Adults Developmental Years). This project was a collaborative, multi-site study that was conducted by a consortium of developmental and family scholars to understand the individual and relationship factors that support university students' adjustment and transition to adulthood. The sample of emerging adults used in the current study was composed of 792 undergraduate and graduate students (547 women, 243 men, 1 transgendered person, and 1 person who identified as other). The mean age of the sample was 19.61 years $(\mathrm{SD}=1.86)$, ranging from 18 to 29 years. The participants were recruited from four American universities ( $n s=151,289,240$, and 112 respectively). Religious affiliations varied as follows: $18.8 \%$ Conservative Christian, 30.3\% Roman Catholic, 14\% Liberal Christian, $11.5 \%$ other faiths, $6.8 \%$ Agnostic, $4.9 \%$ Atheist, and no affiliation $13.5 \%$. Most participants were European American (79\%); however, there were also participants that identified as Asian American (9\%), African American (4\%), Latino American (3\%), and "mixed/biracial" or other (3\%). The response rate was approximately 59\% overall but varied from site to site (ranging from 50 to $71 \%$ ).

\section{Procedure}

The participants completed the survey online through an online tool developed by a computer science consultant specifically for this project. The survey contained a battery of 448 items that ranged from demographics to behaviors, temperament, parent-child relationship qualities, and media use. Participants were recruited through announcements of the study to each institution's undergraduate population (primarily through Psychology courses) through a flier. Informed consent was obtained online prior to beginning the questionnaires. The survey took approximately $45 \mathrm{~min}$ to complete, and in exchange for participants' time, they were offered course credit or extra credit, depending upon the site.

\section{Measures}

\section{Religiousness}

Participants completed three items to assess religiousness. These items were frequency of prayer, frequency of church attendance, and attending religious/spiritual activities with others. All items were scored on a 5-point Likert scale with higher scores reflecting greater levels of religiousness. To understand the sample's religiousness more fully, descriptives on each of these items are specified here. Participants reported higher levels of prayer $(M=3.36, S D=1.92)$, moderate levels of attending church $(M=2.36, S D=1.29)$, and did not frequently participate in spiritual activities with at least one other person $(M=1.92, S D=1.36)$. Overall, participants' self-reported themselves to be moderately religious $(M=2.55, S D=1.33)$. All three items were averaged to yield a single score for religiousness. The Cronbach's alpha for this measure was $\alpha=.89$. Concerning validity, items of similar nature to items employed in the present study have displayed validity as evidenced by correlations with health outcomes (Bowie et al. 2017). Additionally, emerging adults with high levels of religious practices perceived morality to be a more important perceived competence than did those with low or medium religious practices (Barry and Nelson 2008). Further, retrospective accounts of childhood family faith activities predicted emerging adults' future religious practices (after accounting for T1 religious practices; Barry et al. 2013). 


\section{Spirituality}

Participants completed the 12-item adapted version of the Spiritual Involvement and Beliefs Scale (Hatch et al. 1998). The original scale was a 16-question scale that tapped into the dimensions of external/ritual, internal/fluid, existential/ meditative, and humility/personal application. Since Hatch et al. (1998) found the humility scale to lack validity, it was omitted from this study. They also found spirituality to be valid among diverse religious groups, and to be correlated to spiritual well-being $(r=.80)$, although Gilliam and colleagues (2008) found it correlated to personal-emotional adjustment $(r=.20)$. The participants rated items on a fivepoint scale ranging from one (strongly disagree) to five (strongly agree). The appropriate items were reverse scored. Items were averaged to yield a single score for spirituality. Cronbach's alpha for the scale was $\alpha=0.91$. A sample question is: "I believe there is a power greater than myself."

\section{Self-worth}

Participants completed the self-worth subscale of the Self Perception Profile for College Students scale (Neeman and Harter 1986). This subscale was adapted to be five single statements, such as "I am happy being the way I am" rather than the opposing statements that individuals had to choose which statement was most like them and then to what extent. This adaptation resulted in a similar continuous variable (with high scores indicating high levels of self-worth), even though the presentation differed slightly. The scale ranged from one (not very true of me) to four (very true of me). The appropriate items were reverse scored. Items were averaged to yield a single score for self-worth. Cronbach's alpha for the scale was $\alpha=0.84$. This adaptation, as has been used in previous studies (Nelson et al. 2010), resulted in expected relations among variables. Specifically, they found that Mormon men who did not view pornography reported higher levels of self-worth than did those who did view it.

\section{Identity}

Participants completed the shortened version of the Ego Identity Process Questionnaire (Balistreri and Busch-Rossnagel 1995). Questions addressed identity beliefs concerning dating, occupation, and values. Four of these items were averaged to yield identity exploration (e.g., "I have tried to learn about different occupational fields to find the best one for me."; $\alpha=0.65$ ), and the eight other items were averaged to yield identity commitment (e.g., "There has never been a need to question my values."; in the current study, $\alpha=0.72$ ). Participants were asked to rate items on a one (strongly disagree) to six (strongly agree) scale. The appropriate items were reverse scored. With respect to validity, Balistreri and
Busch-Rossnagel (1995) found identity exploration to be related negatively to authoritarianism $(r=-.18)$, but positively related to identity commitment for men $(r=.37)$.

\section{Depressive Symptoms}

Using an abbreviated version of the original Center for Epidemiological Studies-Depression Scale (Radloff 1977), participants rated eight statements pertaining to 'How often did this happen in the past week?' Sample items include "I felt sad" or "I felt lonely." Participants rated the frequency of these items on a scale of one (never) to three (most of the time). The appropriate items were reverse scored. Items were averaged. Cronbach's alpha was $\alpha=0.73$ for this scale. Construct validity of the scale has also been demonstrated, in that, men who did not view pornography reported lower levels of depression than did those who viewed it in a Mormon university sample (Nelson et al. 2010).

\section{Data Analysis Plan}

First, descriptive statistics (i.e., means, standard deviations) and bivariate correlations were computed to explore the nature of religiousness, spirituality, and adjustment among university-attending emerging adults and to determine if there were any anomalies within these data which might have limited the utility of cluster analysis. Second, a cluster analysis was used to determine the various profiles of religiousness, spirituality, and psychological adjustment within university-age emerging adults.

\section{Results}

\section{Preliminary Analyses}

Descriptive analyses were performed on all variables, see Table 1. As each survey employed was relatively short, average values were computed for each variable instead of using a composite score to avoid any high or low endorsement of any individual question from skewing that participant's score on the given variable. To explore the relations between adjustment variables as well as religiousness and spirituality, a series of Pearson $r$ correlations were computed (see Table 2). Many significant correlations were observed among variables, but only one potential instance of collinearity between religiousness and spirituality $(r=.76)$ was identified. Using the criteria specified by Sambandam (2003), the value was below the established threshold of $r=.80$. Nonetheless, given the theoretical differences for $\mathrm{R} / \mathrm{S}$ (Pargament et al. 2013), it was advantageous to include both variables in the cluster analysis. 
Table 1 Descriptives

\begin{tabular}{lllll}
\hline Variable & $n$ & $M$ & $S D$ & Range \\
\hline 1. Age & 792 & 19.61 years & 1.86 & $18-29$ \\
2. Gender & 547 female & & & \\
& 243 male & & & \\
& 1 trans & & & \\
& 1 other & & & \\
3. Religious beliefs & 792 & 3.30 & 1.30 & $1-6$ \\
4. Spiritual beliefs & 792 & 3.30 & .84 & $1-5$ \\
5. Self-worth & 790 & 3.28 & .60 & $1-4$ \\
6. Identity exploration & 790 & 4.11 & .84 & $1-6$ \\
7. Identity commitment & 790 & 3.80 & .82 & $1.13-6$ \\
8. Depression & 791 & 1.57 & .38 & $1-2.86$ \\
\hline
\end{tabular}

\section{Cluster Analysis}

Cluster Analysis was conducted and reported on according to recommendations provided by Clatworthy et al. (2005). A Two-Step Cluster Analysis was conducted to identify any unique profiles of religiousness, spirituality, depressive symptoms, self-worth, identity exploration, and identity commitment among emerging adults. All variables were standardized prior to analysis. Distance between clusters was computed using log-likelihood calculation. Clusters were determined using Silhouette measure of cohesion and separation. There were three distinct, yet very similar, clusters within these data, Silhouette $=0.3$.

\section{Differences in Religiousness, Spirituality, and Adjustment Among Clusters}

To determine the differences between these clusters, a MANOVA was conducted to explore differences in religiousness, spirituality, depressive symptoms, self-worth, identity exploration, and identity commitment across the three clusters. Results were significant, Wilks $\lambda=0.16$, $F(12,1564)=199.49, p<.01$, partial $\eta^{2}=.61$, observed power $=1.00$. Table 3 presented the differences between the three clusters across all variables, and finds self-worth, identity commitment (but not identity exploration), depressive symptoms, spirituality, and religiousness significantly differed across cluster membership.

Tukey LSD post hoc analyses were used to determine differences across clusters between variables. As shown in Table 1, self-worth was highest in cluster 2 and lowest in cluster 1 . Identity commitment was highest in cluster 3 and lowest in cluster 1. Depressive symptoms were highest in cluster 1 and lowest in cluster 2 . Spirituality was highest in cluster 3 and lowest in cluster 2 . Religiousness was highest in cluster 3 and lowest in cluster 1. Cluster 1 displayed low self-worth, low identity commitment, high depression, moderate spirituality, moderate religiousness. Cluster 2 displayed high self-worth, high identity commitment, low depression, low spirituality, low religiousness. Cluster 3 displayed moderate self-worth, moderate identity commitment, moderate depression, high spirituality, high religiousness.

\section{Three Adjustment Profiles}

Given the results of the Cluster Analysis combined with the results of the MANOVA, three distinct but similar profiles of adjustment were observed. Two profiles of positive psychological adjustment were seen. Cluster 2 was called the Well-adjusted non-religious and non-spiritual group as individuals within this group displayed high self-worth, high identity commitment, low depression, low spirituality, low religiousness. Cluster 3 was labeled the Adjusted high religious and high spiritual group as individuals within this group displayed high spirituality, high religiousness, moderate self-worth, moderate identity commitment, and moderate depression. There was one profile of low psychological adjustment. Accordingly, Cluster 1 was labeled the Low-adjusted moderate religious and moderate spiritual group as individuals within this group displayed high depression, moderate religiousness, moderate spirituality, low self-worth, and low identity commitment.
Table 2 Pearson $r$ correlations of key study variables

\begin{tabular}{|c|c|c|c|c|c|c|}
\hline & Self-worth & $\begin{array}{l}\text { Identity } \\
\text { explora- } \\
\text { tion }\end{array}$ & $\begin{array}{l}\text { Identity } \\
\text { commit- } \\
\text { ment }\end{array}$ & Depression & Spirituality & Religiousness \\
\hline Self-worth & - & .05 & $.31 * *$ & $-.51 * *$ & $.13 * *$ & $.07 *$ \\
\hline Identity Exploration & & - & -.04 & $-.08^{*}$ & .04 & .00 \\
\hline Identity Commitment & & & - & $-.21 * *$ & $-.25 * *$ & $-.25 * *$ \\
\hline Depression & & & & - & -.01 & -.02 \\
\hline Spirituality & & & & & - & $.76^{* *}$ \\
\hline Religiousness & & & & & & - \\
\hline
\end{tabular}

$* p<.05, * * p<.01$ 
Table 3 Table of differences between the three clusters

\begin{tabular}{|c|c|c|c|c|c|}
\hline Variable & $\begin{array}{l}\text { Cluster } 1 \text { low adjusted } \\
M(S D)\end{array}$ & $\begin{array}{l}\text { Cluster } 2 \text { well adjusted } \\
M(S D)\end{array}$ & $\begin{array}{l}\text { Cluster } 3 \text { adjusted } \\
M(S D)\end{array}$ & $F$ & Partial $\eta^{2}$ \\
\hline Self-worth & $2.80(0.56)^{\mathrm{C}}$ & $3.69(0.27)^{\mathrm{A}}$ & $3.56(0.36)^{\mathrm{B}}$ & $345.76^{* * *}$ & 0.47 \\
\hline Identity commitment & $3.31(0.67)^{\mathrm{C}}$ & $3.91(0.70)^{\mathrm{B}}$ & $4.32(0.70)^{\mathrm{A}}$ & $155.35^{* * *}$ & 0.28 \\
\hline Identity exploration & $4.09(0.85)$ & $4.14(0.79)$ & $4.12(0.88)$ & 0.24 & 0.01 \\
\hline Depressive symptoms & $1.81(0.35)^{\mathrm{A}}$ & $1.29(0.22)^{\mathrm{C}}$ & $1.44(0.29)^{\mathrm{B}}$ & $252.35 * * *$ & 0.39 \\
\hline Religiousness & $2.14(1.10)^{\mathrm{B}}$ & $1.53(0.56)^{\mathrm{C}}$ & $3.92(0.87)^{\mathrm{A}}$ & $371.90 * * *$ & 0.49 \\
\hline Spirituality & $3.05(0.67)^{\mathrm{B}}$ & $2.68(0.67)^{\mathrm{C}}$ & $4.12(0.44)^{\mathrm{A}}$ & $458.00 * * *$ & 0.54 \\
\hline
\end{tabular}

Cluster 1 (low adjusted) consisted of moderate religious and moderate spiritual. Cluster 2 (well adjusted) consisted of non-religious and nonspiritual persons. Cluster 3 (adjusted) consisted of high religious and spiritual persons

Means with different superscripts are significantly different from each other

$* p<.05, * * p<.01, * * * p<.001$

\section{Discussion}

The purpose of this study was to employ a cluster analysis to identify different profiles of R/S and psychological adjustment in emerging adulthood. Although past lines of research employing variable-centered approaches have found links between R/S and indices of adjustment and maladjustment, no study has attempted to take a person-centered approach in attempting to examine the complexity in the relations of R/S and adjustment. Hence, in identifying three different profiles of R/S and psychological adjustment, the results contribute significantly to our understanding of R/S during the third decade of life. Specifically, the present study found distinct profiles that point to two patterns of positive adjustment and one that reflected low levels of adjustment. Individuals from the Well-adjusted non-religious and non-spiritual group displayed high levels of psychological adjustment (lower depressive symptoms, higher self-worth, and higher identity commitment). Conversely, the Adjusted high religious and high spiritual individuals displayed greater psychological adjustment (i.e., moderate levels of depressive symptoms, self-worth, and identity commitment). Lastly, one pattern of individuals with negative psychological adjustment was found; individuals from the Low-adjusted moderate religious and moderate spiritual were moderately religious and spiritual but displayed the highest levels of depression and lowest levels of identity commitment, and low self-worth.

\section{Comparisons Across Profiles}

Although we expected to find a large variance in our measures of emerging adults' $\mathrm{R} / \mathrm{S}$, particularly due to the rising proportion of emerging adults in the US who consider themselves "more spiritual than religious" (Smith and Snell 2009), we found only groups of emerging adults with comparable R/S levels. Few individuals displayed divergent profiles of R/S. In terms of the Low-adjusted moderate religious and moderate spiritual cluster, these individuals displayed the highest levels of depressive symptoms, and lowest levels of self-worth and identify commitment. Surprisingly, these individuals displayed moderate levels of $\mathrm{R} / \mathrm{S}$ compared to the other two clusters who exhibited the highest levels of adjustment either had high or low levels of R/S but the profile faring the worst had moderate levels of both R/S. It may be that these individuals from Cluster 1 (Low Adjustment) are comparable to what Smith and Snell (2009) refer to as the sporadic (17.9\% of their total sample from the National Study of Youth and Religion) who attend services a few times a year, whose faith is somewhat, not very, or not important, and closeness to God, prayer, and scripture reading is quite variable. This profile of emerging adults, therefore, has a basis of their faith tradition from which can guide their future behavior. Therefore, they fared worse because their faith is somewhat a part of their lives, but not fully integrated, which results in potential areas for cognitive dissonance between their beliefs and likely their behavior. This is akin to a study by Nelson et al. (2010) where emerging-adult Mormon men who engaged in behavior opposed by their religion fared psychologically worse than comparable Mormon men who did not engage in such behavior. Scholars may seek to replicate this unusual profile of religiousness, spirituality, and adjustment.

In terms of the two-positive adjustment profile, individuals from the Well-adjusted non-religious and non-spiritual cluster and the Adjusted high religious and high spiritual profiles both displayed greater levels of psychological adjustment than individuals in the Low-adjusted moderate religious and moderate spiritual profile. It is difficult to say which profile of adjustment (Well-adjusted non-religious and non-spiritual vs. high religious and high spiritual) is most positive given the difference between these two profiles is very low as seen by the silhouette measure of cohesion value of 0.3 . The Well-adjusted non-religious and nonspiritual profile displayed greater self-worth, lower identity 
commitment, and lower depressive symptoms than Adjusted high religious and high spiritual profile. Thus, the Welladjusted non-religious and non-spiritual profile has more positive adjustment in two of three adjustment areas relative to the high religious profile. This is not enough at this juncture to say that the Well-adjusted non-religious and nonspiritual profile is significantly preferable to the Adjusted high religious and high spiritual profile.

More importantly, the current study's findings illustrate that adjustment can take numerous forms. Although emerging adults' $\mathrm{R} / \mathrm{S}$ often is associated with adjustment (MagyarRussell et al. 2014), emerging adults who are "nones" have often been found to fare well psychologically, particularly among those who have done the important work of meaningmaking (Zuckerman et al. 2016). Thus, many pathways can exist for emerging adults to experience positive psychological adjustment. It is important though for scholars to investigate these profiles as it bears on other indices of adjustment and to follow these individuals of differing profiles across the full decade of emerging adulthood to determine if one profile is in fact preferable to the other.

\section{Mechanisms Underlying Adjustment and R/S Profiles}

Although many different and unusual adjustment profiles were observed in the present study, we strive to understand the possible mechanisms to explain the connection between $\mathrm{R} / \mathrm{S}$ and adjustment. Oleckno and Blacconiere (1991) noted that religiousness was associated with positive health outcomes, yet Zuckerman (2009) noted that a lack of religiousness also yielded positive outcomes.

It is unclear why individuals who reported moderate R/S levels display the poorest psychological adjustment, which could be explained by Pargament's (2002) finding that the impact of religion is associated with one's religious commitment. Individuals who are intrinsic display greater wellbeing compared to those who are superficially religious. This Low-adjustment cluster may reflect this group of individuals who do not display a high degree of religious commitment to benefit from the positive aspects of religion (as seen in cluster 3) yet barely affiliated with the religion to experience the drawbacks of religion (which were avoided in cluster 2).

Among the Adjusted high religious and high spiritual profile, religious individuals who simultaneously report high levels of spirituality often can be characterized as having a deeper penetration of their faith into their being, which in turn promotes their abilities for self-control and selfregulation to manage life's difficulties and live well (i.e., better adjustment; McCullough and Carter 2013). Moreover, highly religious emerging adults have been shown to engage in high levels of coping (Cook et al. 2014). Further, those with high levels of R/S beliefs are likely to be exposed regularly to religious communities and practices wherein religious models promote their social capital; in turn, these experiences can promote their adjustment (King 2008). Thus, scholars should investigate such constructs as self-control, self-regulation, coping, and religious contextual factors while using this exploratory approach to understand profiles of emerging adults' R/S and adjustment.

Among the Well-adjusted non-religious and non-spiritual persons, however, there may be alternative mechanisms explaining this relation. For non-religious individuals, Weber et al. (2012) have identified numerous sources of distress such as negative views stemming from being atheist; yet, a person's conviction in their non-theistic beliefs was associated with high mental health. As such, the degree to which atheist beliefs are held may be a mechanism through which low R/S individuals are associated with positive adjustment, which we suspect is due to their high levels of meaning-making to discern their atheist worldview and in many cases to reject organized religion. In so doing, they often have come to identify their values and beliefs that guide their daily lives (e.g., Zuckerman et al. 2016). As such, the degree to which atheist beliefs are held may be a mechanism through which low R/S individuals experience positive adjustment. For low R/S emerging adults who do not espouse atheism, explanations for these results are less clear. Since many of these young emerging adults are often involved in heightened exploration of values, beliefs, and worldviews (Arnett 2015), many disengage from organized religion as they focus on the immediate transitions of school, work, and peer group. Thus, in the short term their adjustment may be acceptable; however, Magyar-Russell et al. (2014) would suggest their adjustment in the longterm would not remain high. Indeed, future work is needed among this subgroup of individuals to understand better the mechanisms by which positive adjustment can occur.

\section{Limitation and Future Directions}

Since few individuals displayed divergent profiles of R/S, we attribute this absence in part to the R/S measures used, but also to the sample's age. As younger emerging adults, their levels of spirituality were less than what they are likely to become over the third decade (Astin et al. 2011). Indeed, scholars may seek to utilize this cluster analysis approach with more robust measures to determine if there are sizeable groups of persons who report high levels of spirituality, but low levels of religiousness or vice versa. Additionally, scholars may seek to use more definitive statistical approaches (e.g., a Latent Profile Analysis or Latent Class Analysis) to build upon this exploratory cluster analysis. However, given that the clusters were so similar, a Latent Profile Analysis or Latent Class Analysis would have reduced these data to 
a one-group solution and any nuances across groups would not be captured.

In the current study, we utilized concurrent data, which prevented an exploration of within-person changes across the emerging-adult years. So, while we were not positing a developmental trajectory between R/S and adjustment, it remains important still to examine if such profiles would have emerged previously in the lifespan or later into emerging adulthood and thereafter. Lastly, the sample consisted of emerging adults who are just beginning to embark upon deeper introspection concerning $\mathrm{R} / \mathrm{S}$ in contrast to those in their later twenties. Given that religious and spiritual development is a life-long journey, and tremendous change occurs within the twenties (Yonker et al. 2012), it is likely that findings would vary across those in their twenties depending upon where the persons are in their R/S. Thus, future research that examines individuals across their twenties is essential to understand these relations more fully.

\section{Implications}

The findings of the current study are useful not only to emerging adults to understand the complex ways in which their R/S are related to their psychological adjustment, but they should inform the work that therapists, youth ministers, and campus ministry staff do to support emerging adults' meaning-making. Simply trying to promote greater R/S for young people will not necessarily increase their adjustment, as evidenced by our findings. Rather, these practitioners need to meet emerging adults where they are at psychologically to promote their meaning-making and answer (or appropriately refer) them to be able to seek full answers to their theological questions. Staying in the conversation with young people is key, regardless of whether that leads them toward or away from commitment in their faith of origin.

\section{Conclusion}

The present study identifies unique profiles of emerging adults' psychosocial adjustment, religiousness, and spirituality. Overall, the findings from this study support the notion that three profiles exist, such that moderate religious and spiritual persons display the lowest levels of adjustment. Conversely, the highly R/S and low R/S profiles display the most positive indicators of psychological adjustment. Consequently, future research that explores such mechanisms of self-regulation, coping, and certainty of beliefs, as well as social support afforded religious and spiritual involvement may be important to explaining emerging adults' psychological adjustment.
Acknowledgement We wish to thank our fellow Project READY collaborators, Laura Padilla-Walker, Brian Willoughby, Jason Carroll, and Stephanie Madsen, and all our Project READY data collection sites.

Funding No external funding for this project.

\section{Compliance with Ethical Standards}

Conflict of interest The authors declare that they have no conflict of interest.

\section{References}

Arnett, J. J. (2015). Emerging adulthood: The winding road from the late teens through the twenties (2nd ed.). New York: Oxford University Press.

Arnett, J. J., \& Jensen, L. A. (2002). A congregation of one. Individualized religious beliefs among emerging adults. Journal of Adolescent Research, 17, 451-467.

Astin, A. W., Astin, H. S., \& Lindholm, J. A. (2011). Cultivating the spirit: How college can enhance students' inner lives. San Francisco, CA: Jossey-Bass.

Balistreri, E., \& Busch-Rossnagel, N. A. (1995). Development and preliminary validation of the ego identity process questionnaire. Journal of Adolescence, 18, 179-192.

Barry, C. M., \& Abo-Zena, M. M. (Eds.). (2014). Emerging adults' religiousness and spirituality: Meaning-making in an age of transition. New York: Oxford University Press.

Barry, C. M., \& Nelson, L. J. (2008). The role of religious beliefs and practices on emerging adults' perceived competencies, perceived importance ratings, and global self-worth. International Journal of Behavioral Development, 32(6), 509-521. https://doi. org/10.1177/0165025408095555.

Barry, C. M., Prenoveau, J. M., \& Diehl, C. L. (2013). The value of walking the walk: The relation between family faith activities and emerging adults' religiousness. Journal of Psychology and Christianity, 32, 206-220.

Benson, J. E., \& Elder, G. H., Jr. (2011). Young adult identities and their pathways: A developmental and life course model. Developmental Psychology, 47(6), 1646-1657. https://doi.org/10.1037/ a0023833.

Bowie, J. V., Parker, L. J., Beadle-Holder, M., Ezema, A., Bruce, M. A., \& Thorpe, R. J. (2017). The influence of religious attendance on smoking among Black men. Substance Use and Misuse, 52(5), 581-586. https://doi.org/10.1080/10826084.2016.1245342.

Boyatzis, C. (2013). The nature and functions of religion and spirituality in children. In K. I. Pargament (Ed.), APA handbook of psychology, religion, and spirituality: Vol. 1. Context, theory, and research (pp. 497-512). Washington, DC: American Psychological Association. https://doi.org/10.1037/14045-001.

Burdette, A. M., Hill, T. D., Ellison, C. G., \& Glenn, N. D. (2009). "Hooking up" at college: Does religion make a difference? Journal for the Scientific Study of Religion, 48, 535-551. https://doi. org/10.1111/j.1468-5906.2009.01464.x.

Clatworthy, J., Buick, D., Hankins, M., Weinman, J., \& Horne, R. (2005). The use and reporting of cluster analysis in health psychology: A review. British Journal of Health Psychology, 10(3), 329-358. https://doi.org/10.1348/135910705X25697.

Cook, K. V., Kimball, C. N., Leonard, K. C., \& Boyatzis, C. J. (2014). The complexity of quest in emerging adults' religiosity, wellbeing, and identity. Journal for the Scientific Study of Religion, $53,73-89$. 
Côté, J. E. (2000). Arrested adulthood the changing nature of maturity and identity. New York: New York University Press. https://doi. org/10.1006/jado.1997.0108.

Ellison, C. G., \& George, L. K. (1994). Religious involvement, social ties, and social support in a Southeastern community. Journal for the Scientific Study of Religion, 33, 46-61.

Erikson, E. (1968). Identity: Youth and crisis. New York: Norton.

Gilliam, A. K., Barry, C. M., \& Bacchus, N. A. (2008). The relation between stress and college adjustment: The moderating role of spirituality. Modern Psychological Studies, 13(2), 84-101.

Good, M., Willoughby, T., \& Fritjers, J. (2009). Just another club? The distinctiveness of the relation between religious service attendance and adolescent psychosocial adjustment. Journal of Youth and Adolescence, 38, 1153-1171. https://doi.org/10.1007/s1096 4-008-9320-9.

Hatch, R. L., Burg, M. A., Naberhaus, D. S., \& Hellmich, L. K. (1998). The spiritual involvement and beliefs scale. Journal of Family Practice, 46, 476-486.

Heintzman, P., \& Mannell, R. C. (2003). Spiritual functions of leisure and spiritual well-being: Coping with time pressure. Leisure Sciences, 25, 207-230.

Hill, P. C., Pargament, K. I., Hood, R. W., McCullough, M. E., Swyers, J. P., Larson, D. B., et al. (2000). Conceptualizing religion and spirituality: Points of commonality, points of departure. Journal for the Theory of Social Behaviour, 30, 51-77. https://doi. org/10.1111/1468-5914.00119.

Jankowski, P. J., Hardy, S. A., Zamboanga, B. L., Ham, L. S., Schwartz, S. J., Kim, S. Y., et al. (2015). Religiousness and level of hazardous alcohol use: A latent profile analysis. Journal of Youth and Adolescence, 44, 1968-1983. https://doi.org/10.1007/s1096 4-015-0302-4.

King, P. E. (2008). Spirituality as fertile ground for positive youth development. In R. M. Lerner, R. W. Roeser, \& E. Phelps (Eds.), Positive youth development and spirituality: From theory to research (pp. 55-73). West Conshohocken, PA: Templeton Foundation Press.

Klemmack, D. L., Roff, L. L., Parker, M. W., Koenig, H. G., Sawyer, P., \& Allman, R. M. (2007). A cluster analysis typology of religiousness/spirituality among older adults. Research on Aging, 2, 163-183.

Koenig, H. G. (2008). Concerns about measuring "spirituality" in research. The Journal of Nervous and Mental Disease, 196, 349355. https://doi.org/10.1097/NMD.0b013e31816ff796.

Kristeller, J. L., Sheets, V., Johnson, T., \& Frank, B. (2011). Understanding religious and spiritual influences on adjustment to cancer: Individual patterns and differences. Journal of Behavioral Medicine, 34(6), 550-561. https://doi.org/10.1007/s1086 5-011-9335-7.

Lewinsohn, P., Gotlib, I., \& Seeley, J. (1997). Depression-related psychosocial variables: Are they specific to depression in adolescents? Journal of Abnormal Psychology, 106, 333-341.

Luyckx, K., Schwartz, S. J., Goossens, L., Soenens, B., \& Beyers, W. (2008). Developmental typologies of identity formation and adjustment in female emerging adults: A latent class growth analysis approach. Journal of Research on Adolescence, 18(4), 595-619. https://doi.org/10.1111/j.1532-7795.2008.00573.x.

Magyar-Russell, G., Deal, P. J., \& Brown, I. T. (2014). Potential and detriments of religiousness and spirituality to emerging adults. In C. M. Barry \& M. M. Abo-Zena (Eds.), Emerging adults' religiousness and spirituality: Meaning-making in an age of transition (pp. 39-55). New York: Oxford University Press.

Marcia, J. E., \& Strayer, J. (1996). Theories and stories. Psychological Inquiry, 7, 346-350. https://doi.org/10.1207/s15327965pli070 4_8.

McCullough, M. E., \& Carter, E. C. (2013). Religion, self-control, and self-regulation: How and why are they related? In K. I.
Pargament (Ed.), APA handbook of psychology, religion, and spirituality: Vol. 1. Context, theory, and research (pp. 123-138). Washington, DC: American Psychological Association. https:// doi.org/10.1037/14045-001.

Neeman, J., \& Harter, S. (1986). Manual for the self-perception profile for college students. Unpublished manuscript, University of Denver, Denver, Colorado. https://doi. org/10.1037/0893-3200.21.4.665

Nelson, L. J. (2014). The role of parents in the religious and spiritual development of emerging adults. In C. M. Barry \& M. M. AboZena (Eds.), Emerging adults' religiousness and spirituality: Meaning-making in an age of transition (pp. 59-75). New York: Oxford University Press.

Nelson, L. J., \& Padilla-Walker, L. M. (2013). Flourishing and floundering in emerging-adult college students. Emerging Adulthood, 1, 67-78.

Nelson, L. J., Padilla-Walker, L. M., \& Carroll, J. S. (2010). "I believe it is wrong but I still do it:" A comparison of religious young men who do versus do not use pornography. Psychology of Religion and Spirituality, 2, 136-147. https://doi.org/10.1037/a0019127.

Oleckno, W. A., \& Blacconiere, M. J. (1991). Relationship of religiosity to wellness and other health-related behaviors and outcomes. Psychological Reports, 68(3), 819-826. https://doi.org/10.2466/ pr0.1991.68.3.819.

Pargament, K. I. (2002). The bitter and the sweet: An evaluation of the costs and benefits of religiousness. Psychological Inquiry, 13(3), 168-181. https://doi.org/10.1207/S15327965PLI1303_02.

Pargament, K. I., Mahoney, A., Exline, J. J., Jones, J. W., \& Shafranske, E. P. (2013). Envisioning an integrative paradigm for the psychology of religion and spirituality. In K. I. Pargament (Ed.), APA handbook of psychology, religion, and spirituality: Vol. 1. Context, theory, and research (pp. 3-19). Washington, DC: American Psychological Association. https://doi.org/10.1037/14045-001.

Pew Forum on Religion and Public Life. (2012, October 9). "Nones" on the rise: One-in-five adults have no religious affiliation. Retrieved from http://www.pewforum.org/unaffiliated/nones-on-the-rise. aspx

Powers, D. V., Cramer, R. J., \& Grubka, J. M. (2007). Spirituality, life stress, and affective well-being. Journal of Psychology and Theology, 35, 235-243.

Radloff, L. S. (1977). The CES-D scale: A self-report depression scale for research in the general population. Applied Psychological Measurement, 1, 385-401. https://doi.org/10.1177/0146621677 00100306

Rew, L., \& Wong, Y. J. (2006). A systematic review of associations among religiosity/spirituality and adolescent health attitudes and behaviors. Journal of Adolescent Health, 38, 433-442. https://doi. org/10.1016/j.jadohealth.2005.02.004.

Salmela-Aro, K., Aunola, K., \& Nurmi, J. (2008). Trajectories of depressive symptoms during emerging adulthood: Antecedents and consequences. European Journal of Developmental Psychology, 5, 439-465.

Sambandam, R. (2003). Cluster analysis gets complicated. Marketing Research, 15(1), 16-21.

Schwartz, S. J., Zamboanga, B. L., Luyckx, K., Meca, A., \& Ritchie, R. (2015). Identity in emerging adulthood: Reviewing the field and looking forward. In J. J. Arnett (Ed.), The Oxford handbook on emerging adulthood (pp. 401-420). New York: Oxford University Press.

Shannon, G., Branscum, P., Taylor, L., Cheney, M., Maness, S. B., Frey, M., et al. (2018). The relationship between parent-young adult religious concord and depression. Journal of Spirituality in Mental Health.. https://doi.org/10.1080/19349637.2018.1549524.

Silverstein, M., \& Bengston, V. L. (2018). Linked religious lives across generational time in family lineages: Grandparents as agents of transmission. In D. F. Alwin, D. H. Felmlee, \& D. A. Kreager 
(Eds.), Social networks and the life course: Integrating the development of human lives and social relational networks (pp. 415429). New York: Springer.

Smith, C., \& Snell, P. (2009). Souls in transition: The religious and spiritual lives of emerging adults. New York: Oxford University Press.

Weber, S. R., Pargament, K. I., Kunik, M. E., Lomax, J. W., \& Stanley, M. A. (2012). Psychological distress among religious nonbelievers: A systematic review. Journal of Religion and Health, 51, 72-86. https://doi.org/10.1007/s10943-011-9541-1.

Yonker, J. E., Schnabelrauch, C. A., \& DeHaan, L. G. (2012). The relationship between spirituality and religiosity on psychological outcomes in adolescents and emerging adults: A meta-analytic review. Journal of Adolescence, 35, 299-314. https://doi. org/10.1016/j.adolescence.2011.08.010.

Zinnbauer, B. J., Pargament, K. I., Cole, C., Rye, M. S., Butter, E. M., Belavich, T. G., et al. (1997). Religion and spirituality:
Unfuzzying the Fuzzy. Journal for the Scientific Study of Religion, 36, 549-564. https://doi.org/10.2307/1387689.

Zuckerman, P. (2009). Atheism, secularity, and well-being: How the findings of social science counter negative stereotypes and assumptions. Sociology Compass, 3(6), 949-971. https://doi.org/ 10.1111/j.1751-9020.2009.00247.x.

Zuckerman, P., Galen, L. W., \& Pasquale, F. L. (2016). The nonreligious: Understanding secular people \& societies. New York: Oxford University Press.

Publisher's Note Springer Nature remains neutral with regard to jurisdictional claims in published maps and institutional affiliations. 